\title{
A hazard-ranking system for pesticides used in Greek agriculture based on their adverse health effects.
}

Maria Chatzaki, Makrina Karaglani, Maria Panagopoulou, Evangelia Nena, Theodoros C. Constantinidis, Ekaterini Chatzaki, Christos Nikolaidis.

\begin{abstract}
Pesticide exposure is a major health and safety issue among farmers across the world. In occupational toxicology and epidemiology, information on exact doses and exposure rates is necessary, in order to identify specific risks at the individual and/or community level. Using a hazard-ranking scheme that takes into account both pesticide use and the possibility of adverse health effects (e.g. cancer, reproductive toxicity and endocrine disruption) can prioritize agrochemicals based on "weighted" estimates of corresponding risks. Here, we have used this methodological approach to assign health hazards for pesticides used in Greek agriculture. Based on this analysis, i) Atrazine, ii) Alachlor, iii) 1,3 Dichloro-propene, iv) Chlorotanolil and $v$ ) Metoalachlor were the top five hazard-adjusted pesticides, as regards the carcinogenic risk; whereas as i) Atrazine, ii) Alachlor, iii) Glyphosate, iv) Mancozeb and v) Fenthion, the top five in the list of endocrine-disruption risks. These data can be used effectively as reference to future occupational/epidemiological studies that focus on adverse health outcomes in agricultural communities.
\end{abstract}

Keywords-hazard, ranking system, pesticide, Greek, agriculture, health, occupational exposure.

\section{Introduction}

Pesticides are used extensively in modern agriculture, as a means to controlling parasites and maximizing crop yields. Global marketing of agrochemicals escalated in the second half of the 20th century, growing into a multi-billion dollar enterprise. Some 2.6 million tons of pesticides are applied annually, with the majority being used in developing countries [1]. Yet, despite the obvious economical benefits, pesticides pose a significant risk to both farmers and agricultural communities around the world.

Maria Chatzaki

Dept of Molecular Biology and Genetics, Democritus University of Thrace Greece
One major obstacle in conducting pesticide exposure research is the extensive variety of plant protection products that are being used, which results in the need of extensive sampling and analyses costs [7]. Many scholars have tried to resolve this issue, by using crude amounts of pesticides applied in a region, but this approach introduces significant biases [8]. Namely, the effect of less potent pesticides could be exaggerated, whereas the impact of some highly toxic pesticides could be missed.

Consequently, listing pesticides based on quantities alone is far from being an efficient method for estimating true exposure risks. On the other hand, a hazard-ranking scheme that takes into account both pesticide use and exposure could essentially provide more accurate estimates. The present study uses this approach to prioritize pesticide health hazards in Greek agriculture for a 12-year period (1992-2003). The top-ranking pesticides for i) carcinogenic risk and ii) endocrine-disrupting potential are presented and specific recommendations concerning the safe use of these products are provided.

\section{Methods}

Data on pesticides used in Greek agriculture were collected from official resources provided by Eurostat [9]. The dataset contains detailed information on the active ingredients used, the quantities applied, and the types of crops treated. IARC and EU-classification schemes were used to attribute a "class" from 1 to 10 to all pesticides with respect to carcinogenic potential $[10,11]$. Cancer slope factors (mg kg-1 day-1) were retrieved from the Integrated Risk Information System (IRIS), and they were used to assign a cancer "potency" weight [12]. The volatilization "flux" (day-1) for each pesticide was calculated using the vapor pressure, water solubility, and soil absorption coefficient, as previously described [13]. Field dissipation half-life (t1/2 days) was employed to assign a "persistence" weight [14].

Makrina Karaglani, Maria Panagopoulou, Evangelia Nena, Theodoros C. Constantinidis, Ekaterini Chatzaki, Christos Nikolaidis

Medical School, Democritus University of Thrace

Greece 
Table 1 Parameters used in the calculation of carcinogenic hazard

\begin{tabular}{cccccc}
\hline & CL & POTENC & FLUX & PERSIST \\
ASS & Y & & ENCE & \\
\hline WEIG & IAR & EU & mg kg-1 & $\begin{array}{c}\text { Volatiliza } \\
\text { tion day-1 }\end{array}$ & $\begin{array}{c}\text { t1/2 } \\
\text { days }\end{array}$ \\
HT & C & & day-1 & $>10-1$ & $>100$ \\
$\mathbf{1 0}$ & 1 & Carc. 1A & $>1$ & $>10-3-10-$ & $76-$ \\
$\mathbf{8}$ & 2A & Carc. 1B & $>0.1-1$ & 1 & 100 \\
& & & & $10-5-10-$ & $51-$ \\
$\mathbf{5}$ & 2B & Carc. 2 & $>0.01-$ & $>10-1$ & \\
& & & 0.1 & 3 & 75 \\
$\mathbf{3}$ & 3 & Carc. 3 & $0.001-$ & $10-5-10-7$ & $25-$ \\
& & & 0.01 & & 50 \\
$\mathbf{1}$ & 4 & N/A & $<0.001$ & $<10-7$ & $<25$ \\
& & & or N/A & & or \\
& & & & & N/A \\
\hline
\end{tabular}

Cancer risk was calculated using the information in Table 1, according to the equation (1):

Cancer Hazard Factor $=($ Class $\times$ Potency $\times$ Flux $\times$ Persistence)/1000

The hazard-adjusted pesticide use was then computed by multiplying the cancer hazard factor by the average amount of pesticides applied over the 12-year period, according to the equation (2):

Hazard-Adjusted Pesticide Use $=$ Cancer Hazard Factor $\times$ Amount Used (tons)

EU-classification of endocrine-disrupting chemicals was used to attribute a "class" from 1 to 10 to all pesticides [15]. Reference Doses (RfDs) were retrieved from the Integrated Risk Information System (IRIS), in order to assign a "potency" weight [16]. Volatilization "flux" (day-1) and "persistence" ( $\mathrm{t} 1 / 2$ days) for each pesticide were the same as described above.

Table 2 Parameters used in the calculation of endocrine disrupting hazard

\begin{tabular}{ccccc}
\hline & $\begin{array}{c}\text { CLAS } \\
\text { S }\end{array}$ & $\begin{array}{c}\text { POTENC } \\
\text { Y }\end{array}$ & FLUX & $\begin{array}{c}\text { PERSISTEN } \\
\text { CE }\end{array}$ \\
\hline WEIG & EU & mg kg-1 & Volatilizatio & t1/2 days \\
HT & & day-1 & n day-1 & \\
$\mathbf{1 0}$ & 1 & $<0.001$ & $>10-1$ & $>100$ \\
$\mathbf{8}$ & 2 & $0.001-$ & $>10-3-10-1$ & $76-100$ \\
& & 0.01 & & \\
$\mathbf{5}$ & $3 \mathrm{a}$ & $>0.01-0.1$ & $>10-5-10-3$ & $51-75$ \\
$\mathbf{3}$ & $3 \mathrm{~b}$ & $>0.1-1$ & $10-5-10-7$ & $25-50$ \\
$\mathbf{1}$ & $\mathrm{N} / \mathrm{A}$ & $>1$ & $<10-7$ & $<25$ or N/A \\
\hline NA=Not available & & &
\end{tabular}

The endocrine disruption hazard was calculated using the information in Table 2, according to the equation (3):

Hazard Factor $=($ Class $\times$ Potency $\times$ Flux $\times$ Persistence) $/ 1000$

The hazard-adjusted pesticide use was then computed by multiplying the hazard factor by the average amount of pesticides applied over the 12-year period, using the equation (4):

Hazard-Adjusted Pesticide Use $=$ Hazard Factor $\times$ Amount Used (tons)

In Table 3, the top-listing pesticides used in Greek agriculture (1992-2003) are shown. Glyphosate ranks first
(217.3 tons), followed by Fenthion (144 tons), Mancozeb (134.7 tons), 1,3 Dichloro-propene (101.8 tons) and Atrazine (89.6 tons).

Table 3 Top-listing pesticides based on absolute amounts used.

\begin{tabular}{ccc}
\hline & PESTICIDE & $\begin{array}{c}\text { AMOUNT } \\
\text { (tons) }\end{array}$ \\
\hline $\mathbf{1}$ & GLYPHOSATE & 217.33 \\
$\mathbf{2}$ & FENTHION & 144.00 \\
$\mathbf{3}$ & MANCOZEB & 134.67 \\
$\mathbf{4}$ & 1,3 DICHLORO- & 101.75 \\
& PROPENE & \\
$\mathbf{5}$ & ATRAZINE & 89.58 \\
$\mathbf{6}$ & PROPINEB & 84.25 \\
$\mathbf{7}$ & METOALACHLOR & 77.50 \\
$\mathbf{8}$ & MECOPROP & 73.67 \\
$\mathbf{9}$ & ALACHLOR & 63.09 \\
$\mathbf{1 0}$ & METAMITRON & 34.17 \\
$\mathbf{1 1}$ & FOSETYL & 32.33 \\
$\mathbf{1 2}$ & CHLORPYRIFOS & 27.75 \\
$\mathbf{1 3}$ & PARATHION & 21.58 \\
& METHYL & 18.38 \\
$\mathbf{1 4}$ & CHLOROTANOLIL \\
$\mathbf{1 5}$ & 2,4-D & 17.75 \\
\hline \multicolumn{3}{c}{}
\end{tabular}

The ranking system differed substantially, when pesticide use was adjusted for carcinogenic potential. The top five pesticides by cancer hazard are presented in Table 4. Namely, Atrazine and Alachlor were $5^{\text {th }}$ and $9^{\text {th }}$ in the overall ranking for total amounts used, but ranked $1^{\text {st }}$ and $2^{\text {nd }}$ respectively, when cancer hazard-adjusted use was considered.

Table 4 Hazard-adjusted use of pesticides based on their carcinogenic potential

\begin{tabular}{cccc}
\hline PESTICIDE & $\begin{array}{c}\text { AMOUNT } \\
\text { USED }\end{array}$ & $\begin{array}{c}\text { HAZARD } \\
\text { FACTOR }\end{array}$ \\
\hline $\mathbf{1}$ & ATRAZINE & 89.6 & 3.2 \\
$\mathbf{2}$ & ALACHLOR & 63.1 & 0.6 \\
$\mathbf{3}$ & 1,3 DICHLORO- & 101.8 & 0.25 \\
& PROPENE & & \\
$\mathbf{4}$ & CHLOROTANOLIL & 18.4 & 0.36 \\
$\mathbf{5}$ & METOALACHLOR & 77.5 & 0.08 \\
\hline
\end{tabular}

Similarly, the top five pesticides for endocrinedisrupting potential were Atrazine and Alachlor followed by Glyphosate, Mancozeb and Fenthion (Table 5).

Table 5 Hazard-adjusted use of pesticides based on endocrine disrupting potential

\begin{tabular}{cccc}
\hline & PESTICIDE & $\begin{array}{c}\text { AMOUNT } \\
\text { USED }\end{array}$ & $\begin{array}{c}\text { HAZARD } \\
\text { FACTOR }\end{array}$ \\
\hline $\mathbf{1}$ & ATRAZINE & 89.6 & 4.0 \\
$\mathbf{2}$ & ALACHLOR & 63.1 & 1.92 \\
$\mathbf{3}$ & GLYPHOSATE & $217.3 *$ & 0.225 \\
$\mathbf{4}$ & MANCOZEB & 134.7 & 0.27 \\
$\mathbf{5}$ & FENTHION & $144^{*}$ & 0.192 \\
\hline *Estimated Amounts & &
\end{tabular}




\section{Discussion}

Based on this ranking system, the most dangerous pesticides, as regards cancer risk and endocrine disruption were identified. Neither the hazard factor alone (potencyweighted) nor the absolute amount used (quantity-weighted) could explain the calculated risk listing. The cancer hazard factors ranged from 0.08 (Metoalachlor) to 3.2 (Atrazine), and the hazard factor for endocrine disruption from 0.192 (Fenthion) to 4.0 (Atrazine). Based on this classification, Alachlor ranks second in hazard-adjusted use for both cancer and endocrine disruption, yet it is 9 th in the list of absolute quantities used. On the other hand, Glyphosate is not as hazardous as Mancozeb based on endocrinedisrupting potential; however its widespread use (top of the list, 217.3 tons) places it higher in the hazard-adjusted scale for endocrine disruption.

The "weight-adjustment" system presented here provides unprecedented information on pesticide use and exposure risks to agricultural professionals and rural communities. As this study shows, commonly used pesticides that are generally considered benign in comparison to organochlorines and organophosphates, such as Glyphozate and Mancozeb, carry a significant burden. Glyphosate and Mancozeb with "known" or "suspected" endocrinedisrupting potential are still widely used in Greek and European agriculture, and the same holds true for Chrolorotanolil and cancer risk. On the contrary, Atrazine, Alachlor and Fenthion are now banned by EU legislation.

Conclusively, the hazard-weighted pesticide use has created different priorities for occupation and environmental health. Prioritizing pesticides using this approach may provide better estimates on potential exposures. Moreover, the likelihood of adverse health effects is better sustained and points specifically to labels that pose the greatest risk.

\section{References}

[1] Alavanja MC. Introduction: pesticides use and exposure extensive worldwide. Rev Environ Health. 2009;24:303-9.

[2] Walt G. WHO's World Health Report 2003. BMJ. 2004;328:6

[3] Cohen M. Environmental toxins and health--the health impact of pesticides. Aust Fam Physician. 2007;36:1002-4.

[4] Fantke P, Friedrich R, Jolliet O. Health impact and damage cost assessment of pesticides in Europe. Environ Int. 2012;49:9-17.

[5] Pratt IS, Barron T. Regulatory recognition of indirect genotoxicity mechanisms in the European Union. Toxicol Lett. 2003;140-141:5362.

[6] Ruzzin J. Public health concern behind the exposure to persistent organic pollutants and the risk of metabolic diseases. BMC Public Health. 2012;12:298

[7] Navarro-Ortega A, Acuna V, Batalla RJ, Blasco J, Conde C, Elorza FJ, et al. Assessing and forecasting the impacts of global change on Mediterranean rivers. The SCARCE Consolider project on Iberian basins. Environ Sci Pollut Res Int. 2012;19:918-33.

[8] Arcury TA, Quandt SA, Barr DB, Hoppin JA, McCauley L, Grzywacz JG, et al. Farmworker exposure to pesticides: methodologic issues for the collection of comparable data. Environ Health Perspect. 2006;114:923-8.

[9] Balderacchi M, Trevisan M. Comments on pesticide risk assessment by the revision of Directive EU 91/414. Environ Sci Pollut Res Int. 2010;17:523-8.

[10] Damalas CA, Eleftherohorinos IG. Pesticide exposure, safety issues, and risk assessment indicators. Int $\mathbf{J}$ Environ Res Public Health. 2011;8:1402-19
[11] IARC (International Agency for Research on Cancer). Agents classified by the IARC monographs volumes 1-104. World Health Organization, Lyon, France; 2011.

[12] Gunier RB, Harnly ME, Reynolds P, Hertz A, Von Behren J. Agricultural pesticide use in California: pesticide prioritization, use densities, and population distributions for a childhood cancer study. Environ Health Perspect. 2001;109:1071-8.

[13] Glotfelty DEL, M.M.; Jersey, J.; Taylor, A.W. Volatilization and wind erosion of soil surface applied atrazine, simazine, alachlor, and toxaphene J Agric Food Chem. 1989;37:5.

[14] U.S. Department of Agriculture [Internet]. Pesticide Properties Database. 2009 [cited 2001 Mar 9]. Available from: http://wizard.arsusda.gov/ acsl/ppdb3.html

[15] Petersen GI, Gustavson K. Study on enhancing the endocrine disruptor priority list with a focus on low production volume chemicals. Revised report to DG environment. European Commission, Horsholm, Denmark; 2007.

[16] U.S. EPA. Reference Dose (Rfd): description and usage in health risk assessments. Integrated Risk Information System; 1993.

About Author (s):

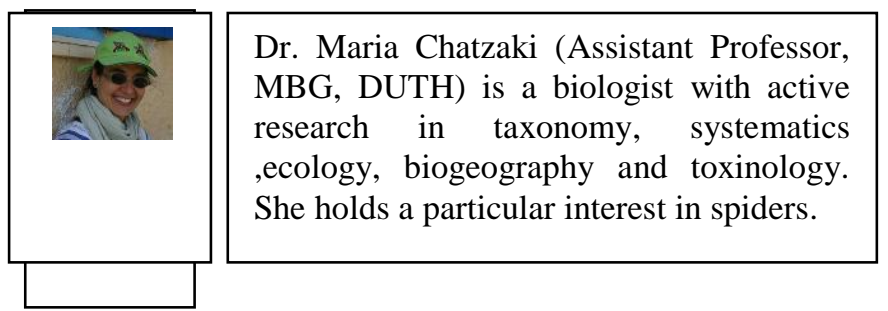

